\title{
Socially Accountable Medical Education: Our Story Might Not Be Yours
}

\author{
Brian M. Ross ${ }^{1} \&$ Erin Cameron ${ }^{1}$ \\ ${ }^{1}$ Northern Ontario School of Medicine and Faculty of Education, Lakehead University, Thunder Bay, Ontario, \\ Canada \\ Correspondence: Prof. Brian M. Ross, Division of Medical Sciences, Northern Ontario School of Medicine, \\ Lakehead University, 955 Oliver Road, Thunder Bay, Ontario, P7B5E1, Canada. Tel: 807-766-7394. E-mail: \\ bross@nosm.ca
}

Received: November 21, 2020

Accepted: December 20, 2020 Online Published: January 6, 2021

doi:10.5539/hes.v11n1p114

URL: https://doi.org/10.5539/hes.v11n1p114

\begin{abstract}
Socially Accountable Medical Education is a global educational movement transforming the development and delivery of medical schools in higher education. It is described as an upstream policy approach that seeks to align medical education and local community healthcare needs. To better understand social accountability as a policy initiative, we conducted a narrative review to identify key themes in the literature around frameworks of implementation. Our findings illustrate that social accountability has been mostly defined to date in terms of outcomes and related-actions and that there is a lack of focus on critical social constructs, such as power and place, that can reorient processes and inequities within health systems and educational institutions. We conclude that while socially accountable medical education is a promising paradigm shift in higher education, we call for a more complexified, contextualized, and nuanced approach.
\end{abstract}

Keywords: medical education, social accountability, higher education, narrative review, place-based policy

\section{Introduction}

Better alignment between medical education and the health care needs of society is now considered a key pathway for improving human health (Boelen \& Heck, 1995; WHO, 1978). In the last decade, this alignment, termed Socially Accountable Medical Education (SAME), has become a priority in medical school reform and accreditation standards (Boelen \& Wollard, 2009, 2010). Medical schools who adopt a social accountability mandate aim to educate future and current physicians to deliver evidence-based and culturally-relevant healthcare to local communities in an equitable and cost-effective manner (Boelen \& Heck, 1995; Boelen et al., 2016). As an upstream social policy influencing higher education globally (Boelen \& Wollard, 2011), SAME has become a catalyst for the development of new medical schools in geographically and historically disadvantaged settings (Strasser et al., 2013). As SAME has become more institutionalized and standardized, concerns about the future of SAME as a novel context citizen engaged approach are growing (Joshi \& Houtzager, 2012 ). While the convenience and efficiency of shared standards and outcomes are often welcomed in medicine, they increasingly stand in tension with the contextual focus of SAME (Bates et al., 2019). Efforts to reconcile the goals of standardization and social accountability is urgently needed to be able to advance our understanding of SAME and its educational impact on students, faculty, and communities.

\section{Method}

The primary aim of this review was to identify the nature of the meaning and frameworks for implementation of social accountability in medical education - the 'what' and the 'how'. Search terms included 'social accountability', 'social responsibility', 'medicine', 'medical education' and 'healthcare'. A narrative review is helpful for summarizing different primary studies and literature, particularly ones that include multiple sources (Green, Johnson, \& Adams, 2006). Seminal papers from 1990-date were identified and then compared with other existing literature databases (Cooper, 2016). Results of the search were sorted according to relevance and supplemented by reviewing the list of publications relevant to SAME compiled by the Training for Health Equity Network, a group of medical leaders, administrators, and researchers invested in social accountability (THEnet, 2018). Each paper was read to discern the definition of SAME referenced to the literature and/or developed within the paper, along with the various frameworks identified for effective implementation of SAME. 
Additionally, notes were taken and tabulated until data saturation was reached. In total, 32 articles were synthesized and included in this review.

\section{Results}

Three main themes emerged in the review. The themes not only illustrate the different ways SAME has been constructed in the literature, but they highlight the nuances, complexities, and tensions that have emerged within the field around terminology (definitions), outcomes (measurement), and actions (implementation), which will be further addressed in the discussion.

\subsection{Defining SA: WHO Is Driving the Field}

The review highlighted the heterogenous application of terminology in the field. The World Health Organisation (WHO), which gets most frequently cited in the literature, has defined SAME as medical schools having "the obligation to direct their education, research and service activities towards addressing the priority health concerns of the community, region, and/or nation they have a mandate to serve" (Boelen \& Heck, 1995). This definition, and the meaning it ascribes to SAME, has been adopted by most medical schools who declare a social accountability mandate (for examples see references Leigh-Hunt et al., 2015; Talib et al., 2017). Here, the definition identifies the broad outcomes of SAME as addressing local health concerns, and by implication that physician training should have a significant positive impact on people's health. The WHO continues, however, saying that the priority health concerns be identified "jointly by governments, health care organizations, health professionals and the public" (Boelen \& Heck, 1995), thereby directing a school to consider how social accountability is to be implemented within a program. Here, in addition to outcomes, the WHO definition highlights the need for collaborative actions that support these outcomes.

While the WHO definition is widely used, the dual focus on outcomes and actions within SAME has been further developed and framed within a social obligation continuum; where social responsibility is at the lower end of the continuum and social accountability is at the higher end (Boelen et al., 2012). In doing so, Boelen and colleagues identified more specific outcomes and actions for medical schools to achieve social accountability by: a) graduating 'social change agents', b) having programs that are fully community 'contextualised', and c) having the program's success assessed by 'health partners'. This notion of a SAME continuum has most recently led to checklists and criteria being proposed that identify ways for medical schools to assess their level of social accountability (for examples see Batra et al., 2020; Boelen \& Wollard, 2009; Rourke, 2019), and most recently a checklist for students to assess their school's level of social accountability (Dijk et al., 2017). Notably, all checklists and criteria are all premised on the WHO definition, which makes it clear that WHO is driving SA.

\subsection{Measuring SA: Variable Outcomes}

Another key theme to emerge in the literature is that measurement is a core agenda of SAME. The main outcome of SAME identified in the literature was focused on graduating physicians that are 'fit for purpose' - defined as the capacity to meet the healthcare needs of the communities they serve (McCrea and Murdoch-Eaton, 2014). This is in keeping with the idea that medical schools should primarily be concerned with producing a physician workforce that is qualitatively and quantitatively matched to community needs, to address physician shortages and any 'mis-match' between physician knowledge and skills, and community needs (Grbic et al., 2013; Preston et al 2016; Cometto et al., 2016).

A second outcome measure of SAME is the focus on reducing health inequities, such as those caused by gender, geographic location, socioeconomic class, ethnicity and other social determinants of health (Braveman \& Gruskin, 2003). Reducing health inequities through public health initiatives and the training of physicians to deliver relevant healthcare to historically underserved populations, such as persons living in rural communities or Indigenous peoples, is framed as a key outcome of SAME by many authors (for examples see references Siega-Sur et al., 2017; Reeve et al., 2017; Wooley et al, 2018). This goes beyond outcomes framed in terms of increasing the quality of healthcare, towards a clear goal of reducing morbidity and mortality in populations that experience the highest rates of disease and ill-health. In addition, over and above health inequities, the outcomes of SAME have been expanded to address other aspects of social justice including increasing diversity within the healthcare system, the promotion of gender and socio-economic equity, and improving the overall equity and well-being of society (Puschel et al., 2014; Palsdottir et al. 2016).

\subsection{Implementing SA: Important Considerations}

The actions, like outcomes, identified in the literature for implementing SAME in medical schools are similarly diverse and variable. For example, in terms of the principles underlying the design of the curriculum some programs view student and patient-centred teaching as important, while others use integrated curriculum formats 
(where different courses run in an intermingled and concurrent manner) (Entezari et al., 2009; Ross et al., 2014). The need for the program to be based in the local community, or that most mentors be community-based primary care physicians, is also promoted, particularly when improved health care access and health equity is desired (Talib et al., 2017; Boelen et al., 2012; Palsdottir et al, 2016). In terms of curriculum content, a wide range of elements have been proposed or are being used within SAME, elements such as: an emphasis on the social determinants of health, interprofessionalism and health care teams, primary care, rural practice, a knowledge of the wider health system, several community-based experiences, critical pedagogy, and spending time in clinical settings during the early stages of training (Boelen et al., 2012; Palsdottir et al., 2016; Puschel et al., 2014; Ross, 2015). Moreover, in addition to curriculum content, other aspects of the organisation of a socially accountable school have been put forward including that social accountability be explicitly tied to the governance and operational aspects of the institution, and that social accountability is incorporated into all aspects of the school, both administrative and academic (Preston et al, 2016). Medical school admission processes are also seen as important in SAME with a focus on drawing students from local communities given that evidence has shown these students are more likely to stay and practice in their home communities (Ross et al, 2014).

\section{Discussion}

\subsection{Definitions and Discourses: Should SAME Be the Same?}

While social accountability has been defined as collaboratively identifying and addressing local health needs, published literature on the topic has predominantly taken a biomedical, reductionistic, and standardized approach. While checklists and criteria can be useful in a climate of heightened national accreditation standards, some have argued such approaches fail to respond to the complex community needs and the redistribution of power (Joshi \& Houtager, 2012). Administrative and academic structures within medical schools need to meaningfully engage community (Strasser et al., 2015), with an emphasis on shared power and reciprocity between communities and the academy (Ross, 2018). It has been argued that SAME is contextual and place-based (Ross et al., 2014), meaning that SAME must be grounded in the historical, geographical, social, political, and cultural local contexts. This idea suggests that social accountability can only meaningfully be achieved through organic approaches that are developed, implemented, and assessed through and by local contexts. For this to happen, a deep understanding and commitment to place is critical to moving the social accountability agenda forward in medical education. In other words, the more SAME is reduced to a story about institutional outcomes and actions, we are at risk of undermining and misunderstanding community needs because community is no longer the focus.

A great Canadian author once wrote "the truth about stories is, is that's all we are" (King, 2003). Based on this review, we argue that in order to understand SAME we need to situate it within stories that foreground unique narratives of place and community, with authentic processes that meaningfully engage community voices. In other words, rather than checklists and criteria, localized processes around identifying and sustaining social accountability need to be prioritized. Ultimately, the essence of SAME is that institutions and communities should be able to tell the detailed story of how they co-created their vision of social accountability and what it means within their medical education programs. Put another way, if institutions and communities don't have a shared story, then SAME is not being achieved.

\subsection{Difficult to Measure: Social Accountability for Fitness or Justice}

The proposed measurement outcomes vary from the utilitarian concept of fitness at one end to a desire to address social justice issues within the served society, such as establishing university clinics or schools in disadvantaged communities with the aim of addressing health inequalities. The focus on graduates being 'fit for purpose' is woven into the fabric of the literature and focuses on graduates serving communities and institutions preparing them to do so. Thinking of SAME in this manner does not, however, imbue the concept with any ethical principles or moral agency, particularly the desire to use medical education for the betterment of society which is a recurring theme in the literature (for example see Boelen and Wollard, 2009; Puschel et al., 2014). It is possible, after all, to envisage medical education that only addresses the healthcare priorities of a majority group, while ignoring the needs of disempowered minorities as being 'fit for purpose'. With such an approach there is a risk of trivializing the complexity and moral agency of social accountability. This was not what the originators of SAME had in mind given that many proponents of SAME are concerned with social justice as its prime mover (Boelen \& Wollard 2010). There is a growing need to identify ways to avoid reductionistic approaches that overemphasize standardization and perpetuate normative ideas and judgements around what constitutes "good" and "bad" social accountability. Instead, we need to find critical reflexive approaches that will help us pay attention to who has and is given the power within social accountability, while also understanding the 
cultural-economic resources required to develop and sustain such an agenda (Ritz et al, 2014; Ellaway, 2017). These approaches need to be embedded into everyday processes that help to redefine what community engagement means in the academy.

The other outcome that is often mentioned in the literature but not thoroughly addressed is health outcomes. While the health of individuals and communities is often deemed the most authentic measure of SAME, it was rarely mentioned that such measures will take decades to change and will indeed vary between communities.

\subsection{Implementing Social Accountability: Agency of Individuals or Institutions?}

Although varied, the above examples of putting SAME-into-action can be viewed as approaches for preparing physicians to understand and know how to meet the needs of their local community. It is notable, however, that some involved in SAME (Rudolf et al, 2014) view this purely educational approach as being insufficient and see social accountability as requiring direct action by medical professionals as opposed to relying just on program's ability to graduate local doctors. This can be seen in how medical schools require social accountability not just in teaching and research, but also in service (Boelen \& Heck, 1995). Boelen and colleagues (2012) certainly hint at this dimension of SAME in their recommendation that socially accountable programs need to produce "change agents', that is graduates that actively challenge and modify the health care systems to better serve community needs. This is in keeping with other authors who view SAME as needing to promote student altruism such as learners taking part in service-learning, volunteerism, and patient advocacy initiatives (Rudolf et al, 2014). Similarly, Preston and colleagues concluded that SAME should prioritise and reward service, particularly public service, by all members of the school community including the faculty (Preston et al., 2016). Rudolf and colleagues (Rudolf et al., 2014) also contend, however, that a socially accountable medical school should engage in direct action as a matter of institutional agency. For example, the medical school should itself engage in targeted interventions aimed at reducing health inequities, such as health promotion, or take part in the political process and lobby government to engage in public health interventions or to ensure that enough funding is available for a physician workforce targeted towards underserved and unhealthy populations. Such an overtly activist stance is consistent with being socially accountable in our view but, based on the literature, is certainly not the norm for most faculties of medicine nor does it appear likely to be a component of SAME to which all schools adhere. We conclude, therefore, that like outcomes, there are many possible actions that can be characters in the story of SAME.

\subsection{Concluding Thoughts: Prioritising Processes of Social Accountability over Outcomes and Actions}

This review has illustrated a dialectical uncertainty both in the meaning, outcomes, and implementation of SAME. For some, partnering with the community is the extent to their social accountability, but for others community engagement in curriculum development and activist and political activities are not only expected, but they are the norm. Through this review we argue attempting to standardize what constitutes SAME is not only not possible, but that it is critically misrepresenting SAME, since the actions needed are necessarily dependent on both the desired outcomes, and the social and geographical context within which the school operates. As such, any notion that the meaning and implementation of SAME is, or ever will be, comparable between institutions is a myth.

As has been said by others there is no 'silver bullet' as to how to implement social accountability in medical education (Boelen \& Wollard, 2011). Similarly, there is no 'single story' (Adichie, 2018) of social accountability - rather it needs to be defined by local people, place, and community. It needs to be described in terms of the social, political, cultural, historical contexts, and so on, rather than checklists around implementation. We need to accept that social accountability is context dependent and, to some extent, socially constructed (Dahlsrud, 2008). Applied to medical schools, SAME may be better defined in terms of the processes for determining: (i) the local priority health needs, (ii) how the local priority health needs will be addressed, and (iii) whether the chosen interventions are having their desired impacts. In doing so determining if a medical school is socially accountable is not measurable by external factors but internal factors that become a unique story of place and people. Put another way, we suggest that SAME is best defined and assessed in terms of the presence and functionality of the medical school's systems that aim to impact the actual health of the served populations, framed perhaps in terms of community inclusion and influence. Seen in such a manner policy related to SAME become more about the process of being accountable, and that this must occur through a story about/with/through its local community. SAME policy must therefore focus on how medical schools co-create their educational programs with the served communities, rather than on the educational outcomes and actions.

In summary, our review of the SAME literature indicates that there is a strong "single story" narrative that prioritizes reductionism, uniformity, and comparability across institutions. While this is perhaps not surprising in 
a climate of competencies and standardization, we argue that SAME requires a different way of thinking, and that is is more than a "single story". The common core of SAME is instead a process of listening and engaging with place and people - it is a story of many stories with different tomorrows.

\section{References}

Adichie, C. (2018). The danger of the single story. Ted Talk. Retrieved from https://www.ted.com/talks/chimamanda_adichie_the_danger_of_a_single_story

Bates, J., Schrewe, B., Ellaway, R. H., Teunissen, P. W., \& Watling, C. (2019). Embracing standardisation and contextualisation in medical education. Medical education, 53(1), 15-24. https://doi.org/10.1111/medu.13740

Batra, S., Orban, J., Guterbock, T. M., Butler, L. A., \& Mullan, F. (2020). Social mission metrics: Developing a survey to guide health professions schools. Academic Medicine, 95(12), 1811-1816. https://doi.org/10.1097/ACM.0000000000003324

Boelen, C., Dharamsi, S., \& Gibbs, T. (2012). The social accountability of medical schools and its indicators. Education for Health, 25(3), 180. https://doi.org/10.4103/1357-6283.109785

Boelen, C., \& Heck, J. E. (1995). Defining and measuring the social accountability of medical schools. Geneva: Division of Development of Human for Health. World Health Organization. Retrieved from http://apps.who.int/iris/bitstream/handle/10665/59441/WHO_HRH_95.7.pdf

Boelen, C., \& Woollard, B. (2009). Social accountability and accreditation: a new frontier for educational institutions. Medical Education, 43(9), 887-894. https://doi.org/10.1111/j.1365-2923.2009.03413.x

Boelen, C., \& Woollard, R. F. (2010). Global Consensus for Social Accountability of Medical Schools. Retrieved from http://healthsocialaccountability.sites.olt.ubc.ca/files/2011/06/11-06-07-GCSA-English-pdf-style.pdf

Boelen, C., Pearson, D., Kaufman, A., Rourke, J., Woollard, R., Marsh, D. C., \& Gibbs, T. (2016). Producing a socially accountable medical school: AMEE Guide No. 109. Medical Teacher, 38(11), 1078-1091. https://doi.org/10.1080/0142159X.2016.1219029

Boelen, C., \& Woollard, R. (2011). Social accountability: the extra leap to excellence for educational institutions. Medical Teacher, 33(8), 614-619. https://doi.org/10.3109/0142159X.2011.590248

Braveman, P., \& Gruskin, S. (2003). Defining equity in health. Journal of Epidemiology \& Community Health, 57(4), 254-258. https://doi.org/10.1136/jech.57.4.254

Cooper, I. D. (2016). What is a "mapping study?". Journal of the Medical Library Association, 104(1), 76. https://doi.org/10.3163/1536-5050.104.1.013

Cometto, G., Scheffler, R., \& Bruckner, T. (2016). Health workforce needs, demand and shortages to 2030: an overview of forecasted trends in the global health labour market. World Health Organization. Retrieved from http://www.who.int/hrh/com-heeg/Needs_demands_shortages.pdf

Dahlsrud, A. (2008). How corporate social responsibility is defined: an analysis of 37 definitions. Corporate Social Responsibility and Environmental Management, 15(1), 1-13. https://doi.org/10.1002/csr.132

Dijk, S., Glasner, J., Purdy, K., Bhiri, M., Ramalho, R., \& Ross, S. (2017). Social accountability in medical schools: student toolkit. International Federation of Medical Students' Association. Retrieved from https://ifmsa.org/wp-content/uploads/2017/09/Toolkit-on-Social-Accountability_Final-v.32.pdf

Ellaway, R. H. (2017). Moral agency and the medical education researcher. Medical Education, 51(1), 3-5. https://doi.org/10.1111/medu.12924

Entezari, A., Momtazmanesh, N., Khojasteh, A., \& Einollahi, B. (2009). Toward social accountability of medical education in Iran. Iranian Journal of Public Health, 38(Suppl 1), 27-28.

Grbic, D., Hafferty, F. W., \& Hafferty, P. K. (2013). Medical school mission statements as reflections of institutional identity and educational purpose: a network text analysis. Academic Medicine, 88(6), 852-860. https://doi.org/10.1097/ACM.0b013e31828f603d

Green, B. N., Claire, D. J., \& Alan, A. (2006). Writing narrative literature reviews for peer-reviewed journals: secrets of the trade. Journal of Chiropractic Medicine, 5(3), 101-117. https://doi.org/10.1016/S0899-3467(07)60142-6

Joshi, A., \& Houtzager, P. P. (2012) Widgets or Watchdogs? Conceptual explorations in social accountability. Public Management Review, 14(2), 145-162. https://doi.org/10.1080/14719037.2012.657837 
King, T. (2003). The truth about stories: A native narrative. Toronto: House of Anansi Press. Retrieved from https://bclearningnetwork.com/LOR/media/en09/unit1/the\%20truth\%20about\%20stories\%20A\%20Native $\% 20$ Narrative.pdf

Leigh-Hunt, N., Stroud, L., Eaton, D. M., \& Rudolf, M. (2015). A qualitative study of enablers and barriers influencing the incorporation of social accountability values into organisational culture: a perspective from two medical schools. Israel journal of health policy research, 4(1), 1-8. https://doi.org/10.1186/s13584-015-0044-5

McCrea, M. L., \& Murdoch-Eaton, D. (2014). How do undergraduate medical students perceive social accountability? Medical Teacher, 36(10), 867-875. https://doi.org/10.3109/0142159X.2014.916784

Pálsdóttir, B., Barry, J., Bruno, A., Barr, H., Clithero, A., Cobb, N., De Maeseneer, J., Kiguli-Malwadde, E., Neusy, A.J., Reeves, S., \& Strasser, R. (2016). Training for impact: the socio-economic impact of a fit for purpose health workforce on communities. Human Resources for Health, 14(1), 1-9. https://doi.org/10.1186/s12960-016-0143-6

Preston, R., Larkins, S., Taylor, J., \& Judd, J. (2016). Building blocks for social accountability: a conceptual framework to guide medical schools. BMC medical education, 16(1), 227. https://doi.org/10.1186/s12909-016-0741-y

Puschel, K., Rojas, P., Erazo, A., Thompson, B., Lopez, J., \& Barros, J. (2014). Social accountability of medical schools and academic primary care training in Latin America: principles but not practice. Family Practice, 31(4), 399-408. https://doi.org/10.1093/fampra/cmu010

Reeve, C., Woolley, T., Ross, S. J., Mohammadi, L., Halili Jr, S. B., Cristobal, F., Siega-Sur, J. L, \& Neusy, A. J. (2017). The impact of socially-accountable health professional education: A systematic review of the literature. Medical Teacher, 39(1), 67-73. https://doi.org/10.1080/0142159X.2016.1231914

Ritz, S. A., Beatty, K., \& Ellaway, R. H. (2014). Accounting for social accountability: Developing critiques of social accountability within medical education. Education for Health, 27(2), 152. https://doi.org/10.4103/1357-6283.143747

Ross, B. M. (2015). Critical pedagogy as a means to achieving social accountability in medical education. International Journal of Critical Pedagogy, 6(2), 169-186. Retrieved from http://libjournal.uncg.edu/ijcp/article/viewFile/859/857

Ross, B. M. (2018). The socially accountable professor in higher education. Journal of Education and Learning, 7(5), 181-187. https://doi.org/10.5539/jel.v7n5p181

Ross, S. J., Preston, R., Lindemann, I. C., Matte, M. C., Samson, R., Tandinco, F. D., Larkins, S. L., Pallsdotir, B., \& Neusy, A. J. (2014). The training for health equity network evaluation framework: a pilot study at five health professional schools. Education for Health, 27(2), 116-126. https://doi.org/10.4103/1357-6283.143727

Ross, B. M., Daynard, K., \& Greenwood, D. (2014). Medicine for somewhere: the emergence of place in medical education. Educational Research and Reviews, 9(22), 1250-1265. https://doi.org/10.5897/ERR2014.1948

Rourke, J. (2018). Social accountability: a framework for medical schools to improve the health of the populations they serve. Academic Medicine, 93(8), 1120-1124. https://doi.org/10.1097/ACM.0000000000002239

Rudolf, M. C., Reis, S., Gibbs, T. J., Eaton, D. M., Stone, D., Grady, M., Berlin, A., Blair, M., Essa-Hadad, J., Spitzer-Shohat, S., \& Weingarten, M.(2014). How can medical schools contribute to bringing about health equity? Israel Journal of Health Policy Research, 3(1), 17. https://doi.org/10.1186/2045-4015-3-17

Siega-Sur, J. L., Woolley, T., Ross, S. J., Reeve, C., \& Neusy, A. J. (2017). The impact of socially-accountable, community-engaged medical education on graduates in the Central Philippines: implications for the global rural medical workforce. Medical Teacher, 39(10), 1084-1091. https://doi.org/10.1080/0142159X.2017.1354126

Strasser, R., Hogenbirk, J. C., Minore, B., Marsh, D. C., Berry, S., McCready, W. G., \& Graves, L. (2013). Transforming health professional education through social accountability: Canada's Northern Ontario School of Medicine. Medical Teacher, 35(6), 490-496. https://doi.org/10.3109/0142159X.2013.774334

Strasser, R., Worley, P., Cristobal, F., Marsh, D. C., Berry, S., Strasser, S., \& Ellaway, R. (2015). Putting 
communities in the driver's seat: the realities of community-engaged medical education. Academic Medicine, 90(11), 1466-1470. https://doi.org/10.1097/ACM.0000000000000765

Talib, Z., Palsdottir, B., Briggs, M., Clithero, A., Miniclier, C. N., Marjadi, B., Preston, R., \& Willems, S. (2017). Defining community-engaged health professional education: a step toward building the evidence. Washington, DC: National Academy of Medicine. https://doi.org/10.31478/201701a

THEnet. Resources. (2018). Retrieved from http://thenetcommunity.org/resources/

Woolley, T., Halili, Jr, S. D., Siega-Sur, J. L., Cristobal, F. L., Reeve, C., Ross, S. J., \& Neusy, A. J. (2018). Socially accountable medical education strengthens community health services. Medical Education, 52(4), 391-403. https://doi.org/10.1111/medu.13489

World Health Organization. (2020). The declaration of Alma-Ata: The international conference of primary health care. Alma-Ata, USSR. World Health Organisation. Retrieved from http://www.who.int/publications/almaata_declaration_en.pdf

\section{Copyrights}

Copyright for this article is retained by the author(s), with first publication rights granted to the journal.

This is an open-access article distributed under the terms and conditions of the Creative Commons Attribution license (http://creativecommons.org/licenses/by/4.0/). 